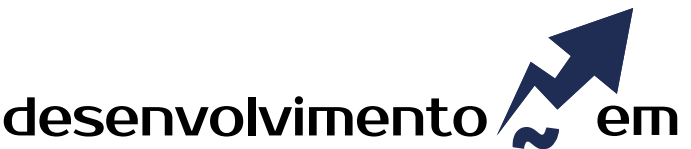 QUESTÃO
}

\section{Acesso e Distribuição do Pronaf entre Agricultores Familiares no Estado de Santa Catarina}

\author{
http://dx.doi.org/10.21527/2237-6453.2020.53.222-244
}

Recebido: $10 / 10 / 2019$

Aceito em: 31/7/2020

\author{
Juliano Luiz Fossá, ${ }^{1}$ Alessandra Matte, ${ }^{2}$ Lauro Francisco Mattei, ${ }^{3}$ Sérgio Schneider ${ }^{4}$
}

\begin{abstract}
RESUMO
Este artigo tem como tema a participação e o acesso da agricultura familiar do Estado de Santa Catarina no Programa Nacional de Fortalecimento da Agricultura Familiar (Pronaf). O objetivo foi analisar a trajetória do acesso e da distribuição do crédito Pronaf naquele Estado. $O$ estudo caracteriza-se por uma abordagem que envolve o uso de métodos tanto quantitativos quanto qualitativos, tendo como delimitação o Estado catarinense e o registro de acesso ao programa Pronaf entre 1996 e 2018. Os dados resultantes da pesquisa foram acessados junto ao Banco Central, considerando os recursos deflacionados pelo INPC para o ano de 2018. Os resultados apontam para crescimento no volume de recursos distribuído no período de 1996 a 2018, contabilizando aproximadamente 6,2 vezes o valor inicial, o equivalente a 619,1\%. Por outro lado, o número de contratos apresentou oscilações, passando de 98 mil em 1996 para 90 mil em 2018, permitindo constatar que o montante acessado por produtor é maior. A maior parcela dos recursos do crédito é destinada ao custeio, o que não impediu o registro de significativos incrementos a partir de 2006 para a linha de crédito de investimento. Constata-se concentração dos financiamentos em culturas/atividades ligadas às grandes cadeias do agronegócio no Estado. É possível concluir que o Pronaf consiste em importante política pública de apoio ao segmento familiar rural do Estado de Santa Catarina, visto que tem aumentando o montante acessado, ao mesmo tempo em que aponta para seletividade dos participantes do Programa e crescimento da necessidade de recursos financeiros.
\end{abstract}

Palavras-chave: Crédito rural. Políticas públicas. Meio rural.

\section{ACCESS AND DISTRIBUTION OF PRONAF BETWEEN FAMILY FARMERS IN THE STATE OF CANTA CATARINA}

\section{ABSTRACT}

This article has as its theme the participation and access of family agriculture in the state of Santa Catarina in the National Program for Strengthening Family Agriculture (Pronaf)., The objective was to analyze the trajectory of access and distribution of Pronaf credit in the state of Santa Catarina. The study is characterized by an approach that involves both the use of quantitative and qualitative methods, having as its boundary the state of Santa Catarina and the registration of access to the Pronaf program between 1996 and 2018. The data resulting from the survey were accessed with the Central Bank, considering the resources deflated by the INPC for the year 2018. The results point to growth in the volume of resources distributed in the period from 1996 to 2018 , accounting for approximately 6.2 times the initial value, equivalent to $619.1 \%$. On the other hand, the number of contracts showed oscillations, from 98 thousand in 1996 to 90 thousand contracts in 2018, allowing to verify that the amount accessed by producer is greater. The largest portion of the credit resources is allocated to funding, which did not prevent the recording of significant increases from 2006 on the investment credit line. There is a concentration of financing in crops / activities linked to large agribusiness chains in the state. It is possible to conclude that Pronaf consists of an important public policy to support the rural family segment of the state of Santa Catarina, since it has increased the amount accessed, at the same time as it points to the selectivity of the program participants and growth in the need for financial resources.

Keywords: Rural credit. Public policy. Countryside.

\footnotetext{
${ }^{1}$ Doutorando em Administração pela Universidade Federal de Santa Catarina (UFSC). Mestre em Políticas Sociais e Dinâmicas Regionais pela Universidade Comunitária da Região de Chapecó (Unochapecó). Universidade Comunitária da Região de Chapecó (Unochapecó). http:// lattes.cnpq.br/4413738329435460. https://orcid.org/0000-0002-9658-4850. j.fossa@unochapeco.edu.br

2 Doutora em Desenvolvimento Rural pela Universidade Federal do Rio Grande do Sul (UFRGS). Professora da Universidade Tecnológica Federal do Paraná (UTFPR). http://lattes.cnpq.br/4891738079879327. https://orcid.org/0000-0002-0502-6643. alessandramatte@yahoo.com.br

${ }^{3}$ Doutor em Ciência Econômica pela Universidade Estadual de Campinas (Unicamp). Professor da Universidade Federal de Santa Catarina (UFSC). http://lattes.cnpq.br/5509228706749288. https://orcid.org/0000-0002-1270-8052. I.matei@ufsc.br

${ }^{4}$ Doutor em Sociologia pela Universidade Federal do Rio Grande do Sul (UFRGS). Professor da Universidade Federal do Rio Grande do Sul (UFRGS). http://lattes.cnpq.br/9374550818298328. https://orcid.org/0000-0002-4353-6732. schneide@ufrgs.br
} 
O Programa Nacional de Fortalecimento da Agricultura Familiar (Pronaf) é um divisor de águas em termos de atenção do Estado brasileiro em relação à trajetória da categoria da agricultura familiar no país. A partir de sua criação, em 1995, o segmento passa a contar com linhas específicas para financiamento das atividades produtivas em relação tanto ao custeio como para investimentos. O Pronaf, no decorrer dos anos, expandiu-se para todo o território nacional e passou por diversas reformulações no sentido de aprimoramento. Desde o início do Programa, contudo, o Estado de Santa Catarina coloca-se como a quinta unidade da Federação em termos de acessos aos recursos do Pronaf (BRASIL, 2019a).

A agricultura familiar catarinense constitui-se como a principal forma de organização da agricultura do Estado, tendo sua importância produtiva, econômica, social e cultural apontada em diferentes estudos acerca dessa categoria social (SANTO, 1999; RENK, 2006; GOULARTI FILHO, 2016). A dinâmica desse segmento envolve significativa diversidade em termos de variedade de produção e também de formas de organização social (MATTEI, 2010).

Conforme os dados recentemente divulgados do Censo Agropecuário Brasileiro, são contabilizados 183.066 estabelecimentos rurais no Estado de Santa Catarina, dos quais 78,1\% (142.987) são classificados como de agricultura familiar (IBGE, 2019). Ao atentar para o número de pessoas ocupadas com atividades rurais, observa-se que a agricultura familiar emprega 364.043 mil pessoas no Estado, correspondente a $72,5 \%$ do total da população ocupada em estabelecimentos rurais. Segundo dados do Censo Agropecuário 2017 (IBGE, 2019), do total de estabelecimentos rurais no Estado de Santa Catarina, 28,9\% acessam alguma forma de financiamento, ou seja, 53.058 estabelecimentos rurais. Destes, 30.801 são obtidos por meio do Pronaf, o que equivale a 58,05\% em relação ao total, superior ao montante acessado no território brasileiro, que representa 40,9\%. Ainda assim, 71\% dos estabelecimentos agropecuários do Estado não buscam financiamento ou empréstimo de recurso financeiro externo à propriedade rural. Ao analisar os dados entre agricultores familiares, constata-se que entre as propriedades que acessam o crédito rural, $61,4 \%$ são obtidos por meio do Pronaf. Ainda segundo o IBGE (2019), os dois principais meios de acesso ao crédito entre esses produtores estão os bancos, com 71,8\% (38.141 estabelecimentos), e as cooperativas de crédito, com 32,8\% (17.392 estabelecimentos).

Ao considerar a significativa participação de Santa Catarina no acesso ao Pronaf emerge a seguinte questão: Como se deu o acesso pelos agricultores familiares e a distribuição por parte do sistema bancário responsável pelo crédito Pronaf em Santa Catarina? O objetivo deste artigo, portanto, é analisar a trajetória do acesso e da distribuição do crédito Pronaf no Estado de Santa Catarina, utilizando indicadores das linhas custeio, investimento e industrialização. Os dados disponíveis permitem discorrer sobre o valor médio dos contratos, distribuição por mesorregião do Estado, finalidade dos financiamentos (produtos), além de serem apontados elementos sobre as linhas alternativas do programa.

Diante do exposto, o artigo está estruturado em quatro seções além desta introdução. Na primeira seção são demonstrados sucintos aspectos referentes à formação da categoria da agricultura familiar no Estado de Santa Catarina, bem como são ilustradas características da produção agropecuária. Na segunda são apresentados elementos 
que constituíram a trajetória do Pronaf como política pública. A terceira seção explicita as informações sobre os procedimentos metodológicos. A seção quatro expõe as análises e indicadores de distribuição do Pronaf crédito de custeio, investimento e industrialização em Santa Catarina por volume de recursos, número de contratos, mesorregião, finalidades e, ainda, aspectos sobre as linhas alternativas do programa. Por fim são elaboradas algumas reflexões a partir dos resultados aqui encontrados que, por sua vez, se constituem nas considerações finais.

\section{ASPECTOS DA TRAJETÓRIA DE CRIAÇÃO E DE ESTABELECIMENTO DO PRONAF NO BRASIL}

Nossa intenção não é recontar a história, mas sim, situar sinteticamente o Pronaf como política pública específica para o conjunto da agricultura familiar, de modo que os dados apresentados na próxima seção sejam de fácil compreensão ao leitor. Assim, é fundamental reconhecer que a política pública do Pronaf é resultado de um histórico significativo de atos e de lutas dos movimentos sociais do campo em torno da valorização do segmento que nas últimas três décadas vem sendo denominado de agricultura familiar.

À margem histórica das prioridades do Estado brasileiro, a agricultura familiar também não se vê contemplada com a institucionalização do Sistema Nacional de Crédito Rural (SNCR) em 1965. Diante deste cenário, por meio dos movimentos sociais do campo, especialmente pela Contag/CUT, inicia-se uma longa marcha histórica reivindicatória para que a agricultura familiar pudesse ter acesso a um tipo de crédito rural adequado a sua realidade social. Em linhas gerais, o segmento não teve espaço na agenda pública no regime ditatorial e somente no final da década de 80 , com a promulgação da Constituição Federal de 1988, consegue se inserir em espaços institucionais de participação e representação institucional. Em complemento a isto, já no início dos anos 90, grandes movimentos nacionais de luta, como o Grito da Terra, ganharam repercussão na sociedade civil e no governo federal à época.

Esse clima favorável, resumidamente, pode ser explicado por três principais fatores, a saber: i) as ações dos segmentos civis organizados do campo, especialmente os sindicatos; ii) uma virada conceitual no meio acadêmico a partir da publicação de estudos em Português que ressignificaram o papel da agricultura familiar no desenvolvimento do país e iii) um estudo realizado pela FAO/Incra que permitiu ao Estado brasileiro uma compreensão maior da magnitude da categoria no interior da agricultura nacional.

A estrutura do programa, bem como seus objetivos e finalidades, foi desenhada a partir de estudos da FAO/Incra e do Programa de Valorização da Pequena Produção Rural (Provape), tendo como principal finalidade a concessão de uma linha de crédito específica para agricultura familiar (BIANCHINI, 2015). Nessa esteira, o Programa Nacional de Fortalecimento da Agricultura Familiar (Pronaf) é estabelecido com o propósito de atender especificamente à ampla categoria da agricultura familiar brasileira. O Programa foi criado a partir do Decreto Presidencial N. 1.946/1996, impulsionado por um clima favorável decorrente do ambiente sociopolítico vivenciado no início dos anos 90 . 
A partir de então, o Programa torna-se a principal forma de financiamentos das atividades produtivas do meio rural familiar, com taxas de juros abaixo das tradicionalmente praticadas pelo mercado financeiro tradicional, com prazos maiores, subsídios e, também, assegurando condições de pagamento adequadas à realidade da agricultura familiar. Com o passar dos anos, especialmente depois de 2003, o Programa expande-se para todas as regiões do país, assumindo capilaridade nacional. Em paralelo a essa expansão, o Programa passou por um conjunto de reformulações com o objetivo de meIhorar as ações e a ampliação de sua cobertura.

Para Mattei (2015, p. 13), como resultado desses avanços "[...] Houve um processo de inclusão de novos agricultores como beneficiários dessa política pública", isso porque, para o autor, o governo federal, a partir de 2003, "[...] elegeu o apoio à agricultura familiar como uma das prioridades de sua política de desenvolvimento rural do país". Ainda nesse sentido, Aquino e Schneider (2015) observam que foi entendido, especialmente pelos gestores públicos, que o Pronaf é uma política pública capaz de estabelecer uma estratégia em âmbito nacional de ampliação da diversidade social da agricultura familiar.

Em uma avaliação geral em relação ao Programa, Grisa e Schneider (2015, p. 29) consideram que "o Pronaf se constitui na principal política agrícola para agricultura familiar (tanto em número de beneficiários, capilaridade nacional e recursos aplicados) [...]". Isso porque, ao longo de sua trajetória, tanto os recursos acessados pelos agricultores familiares quanto o número de contratos efetivados desde o início das operações do Pronaf tiveram incremento significativo e, consequentemente, possibilitaram a expansão do Programa em todas as regiões do país. Na mesma perspectiva, Wanderley (2017, p. 69) afirma que em relação à agricultura familiar "não resta dúvida que o Pronaf representou um salto significativo".

É importante ressaltar, contudo, que alguns dos percursos tomados pelo Programa ao longo dos anos é alvo de críticas consistentes, e tais questões podem ser agrupadas em cinco aspectos principais. O primeiro deles está no direcionamento da maior parte dos recursos ao grupo de agricultores familiares mais capitalizados, especialmente aos pertencentes à região Sul do país (BRASIL, 2019b).

O segundo aspecto relaciona-se à concentração dos recursos nas culturas ligadas às cadeias do agronegócio, ou seja, o Pronaf concentra seus recursos em poucas culturas, como a soja, milho, arroz, cebola e pecuária. Essa condição foi recentemente apontada por Cazella et. al. (2016), como crédito para o "agronegocinho", termo utilizado pelos autores ao referirem-se à replicação do modelo empresarial da agricultura nacional no âmbito da agricultura familiar. Essa reprodução do modelo da grande propriedade implica um alto custo à agricultura familiar, haja vista que coloca sob ameaça a garantia da diversificação produtiva e torna o agricultor familiar dependente de tais rendas, além de inseri-lo na volatilidade e riscos dos mercados globalizados.

O terceiro aspecto pode ser construído à luz da significativa redução do número de contratos efetivados pelo Programa, especialmente a partir de 2015 (consequência também dos dois aspectos apresentados anteriormente). Tal fenômeno indica que, de fato, o Programa tem apresentado dificuldades em manter e ampliar o público atendido por ele. 
O quarto aspecto decorre do terceiro, uma vez que um dos pontos críticos do Programa é a incapacidade de viabilização concreta das linhas alternativas do Programa, por exemplo, Pronaf Eco, Pronaf Agroecologia e Pronaf Semiárido. Em continuidade, as linhas de crédito destinadas a públicos específicos, como o Pronaf Jovem e o Pronaf Mulher, também carecem de uma revisão, pois seus resultados até o momento são insignificantes em comparação com as linhas tradicionais.

O quinto aspecto crítico diz respeito ao ponto de vista cultural e engloba todos os sujeitos que circulam em torno do Pronaf. A destinação adequada dos recursos coloca-se com importância, por isso a fiscalização, apesar de ter avançado nos últimos anos, ainda requer um procedimento mais amplo, em termos de cobertura, e mais próximo, no que diz respeito ao controle. Um segundo elemento que envolve esse aspecto é a orientação do crédito rural: os agentes financeiros que operam o Pronaf devem assumir uma postura orientadora e compreender que o real objetivo da concessão de crédito rural é o desenvolvimento das atividades produtivas do agricultor familiar. Diante do exposto, compreendemos que o Pronaf, na condição de política pública, apesar de representar a principal ação do Estado brasileiro em prol do segmento da agricultura familiar, ainda apresenta desafios importantes a serem superados.

A agricultura do Estado de Santa Catarina está alicerçada desde sua constituição no modelo familiar tanto para fins de produção agropecuária como de reprodução social. Essa condição foi sendo construída ao longo da trajetória de ocupação do território catarinense, especialmente a partir do ano de 1860. É a partir dessa década que se intensifica a chegada de imigrantes europeus, que, em um primeiro momento, ocuparam as regiões litorâneas e gradativamente foram ingressando no interior do Estado. A região Oeste, última do Estado a receber tais imigrantes, passou por processo diferente das demais. Isso porque, devido à sua distância em relação ao litoral catarinense, a chegada desses imigrantes se deu via Rio Grande do Sul, que por sua vez já havia de certa forma esgotado as terras disponíveis para colonização. Esse movimento ocorre nas primeiras décadas do século 20, especialmente pela ação do governo de Santa Catarina e das empresas colonizadoras (WERLANG, 2006; RENK, 2006).

Os dados do Censo Agropecuário de 2017 registram que a produção dos 136.917 estabelecimentos rurais de agricultura familiar do Estado representou $50,7 \%$ do valor bruto da produção agropecuária, atingindo elevada participação na produção dos principais produtos de origem animal e vegetal (IBGE, 2019). Os dados apresentados ressaltam a importância do segmento da agricultura familiar em Santa Catarina. Além disso, nos permitem compreender a contribuição da categoria para geração do produto agropecuário no comparativo com outras formas de agricultura. Por fim, nas palavras de Mattei (2010, p. 12) "[...] a agricultura familiar é a grande responsável pela atual dinamização do setor rural catarinense", afirmação feita a partir de seu estudo sobre as dinâmicas agropecuárias no Estado.

\section{MÉTODO DE PESQUISA}

A aproximação com a realidade mediada pela pesquisa e seus procedimentos metodológicos leva a produzir conhecimentos a partir de experiências em diferentes espaços e contextos histórico-sociais. Em se tratando do conhecimento científico, esse aperfeiçoa o uso da racionalidade ao propor uma forma sistemática, metódica e crítica 
para desvelar e explicar os fenômenos sociais (KOCHE, 2015). A pesquisa aqui apresentada guiou-se nesta perspectiva, sendo realizada por meio de métodos científicos e pela construção do conhecimento a partir da realidade social.

Em termos metodológicos este estudo caracteriza-se como uma pesquisa de abordagem quantitativa e qualitativa. A pesquisa quantitativa apoiou-se na definição de Creswell (2010), considerando-a como um meio para testar teorias objetivas e o exame de relações entre variáveis numéricas. Marconi e Lakatos (2018) definem a abordagem quantitativa como sendo uma descrição objetiva e sistemática do conteúdo apresentado por meio de uma comunicação ou de uma pesquisa. $O$ enfoque qualitativo permite a ação e a análise do pesquisador com toda informação numérica resultante de uma investigação científica. Quanto à qualitativa, foi assumida a perspectiva em que são valorizados os sentidos e os significados de indivíduos ou grupos diante dos problemas sociais (CRESWELL, 2010). A metodologia qualitativa possibilita dois aspectos fundamentais aos pesquisadores: o primeiro diz respeito a um olhar interdisciplinar e o segundo está associado ao pleno aprofundamento do objeto de estudo (DENZIN; LINCOLN, 2010; MARCONI; LAKATOS, 2018). Em outras palavras, é um mergulho em profundidade com objetivo de compreender aspectos da realidade social de uma determinada área do conhecimento.

Em continuidade, tivemos como como orientação inicial a pesquisa bibliográfica nos principais referenciais teóricos sobre a temática. Os dados do acesso ao crédito rural foram obtidos no Banco Central do Brasil. Em relação aos valores monetários, estes foram deflacionados levando em consideração Índice Nacional de Preços ao Consumidor (INPC) para o ano-base de 2018. A série histórica compreende o período de 1996 a 2018.

A delimitação do estudo contempla o Estado de Santa Catarina, região Sul do país. A escolha por este território decorre fundamentalmente por três questões principais, a saber: i) a significativa predominância da agricultura familiar no Estado, herança do processo de ocupação; ii) a expressiva participação de Santa Catarina nos recursos do Pronaf desde o primeiro ano de instauração do Programa; iii) ausência de estudos que demonstrem a realidade social quanto ao acesso e à distribuição de tais recursos no âmbito do Estado de Santa Catarina. A análise dos resultados quantitativos compreendeu o uso de cálculos da estatística descritiva, de modo que as informações qualitativas, obtidas por meio de pesquisa bibliográfica, deram suporte à discussão dos principais resultados. De modo a analisar de forma a compreender a dinâmica de acesso, parte dos resultados é analisado por mesorregião, facilitando a compreensão e correlação com a diversidade de sistemas produtivos presentes no Estado.

\section{ACESSO E DISTRIBUIÇÃO DO CRÉDITO PRONAF EM SANTA CATARINA}

Os dados apresentados nesta seção referem-se à série histórica do programa (1996-2018). Serão evidenciados indicadores quanto ao volume de crédito acessado, número de contratos, valores médios, cobertura e a finalidade do financiamento concedido via Programa no território catarinense. Inicialmente, procuramos caracterizar os agricultores familiares catarinenses que acessaram o Pronaf, e para isso recorremos às variáveis disponíveis na Matriz de Dados do Crédito Rural do Banco Central do. Nossa intenção inicial foi ressaltar as diversas características do público efetivado pelo Pro- 
grama em Santa Catarina. Em segundo lugar, foram apresentadas a evolução e a distribuição tanto dos contratos como dos recursos. $E$, na sequência, as finalidades quanto à destinação das operações do Pronaf em Santa Catarina.

\section{Características Gerais dos Agricultores Familiares que Acessam o Pronaf em Santa Catarina}

As informações a seguir restringem-se ao período mais recente, compreendido entre 2013 e 2018, conforme possibilidade de acesso às informações junto ao Banco Central do Brasil. Pode-se constatar que o acesso ao crédito por meio de pessoa física representa quase a totalidade do público efetivo do Pronaf, na medida em que, do total de 648.868 contratos efetivados em Santa Catarina entre os referidos anos, o montante de 648.857 contratos foram realizados por pessoa física (BRASIL, 2019a). As instituições revestidas de personalidade jurídica realizaram apenas 11 operações de Pronaf no período. Em âmbito de país, os valores nacionais em termos relativos são muito próximos à realidade catarinense, demonstrando que nos últimos seis anos quem acessa de fato o Programa são os agricultores familiares na forma individual.

No que se refere ao acesso por gênero, Santa Catarina apresenta concentração nas operações do Pronaf no sexo masculino. No período em análise, 2013 a 2018, dos 648.857 contratos, $90,5 \%$ foram realizados por pessoas do sexo masculino. No cenário brasileiro, esse percentual é menor, registrando no mesmo período $72,2 \%$ do total de contratos realizados. Quanto aos valores, o acesso pelo público feminino em Santa Catarina registrou apenas $8,9 \%$ do total do crédito acessado. Em âmbito de país, a participação das mulheres nos recursos do Programa sobe para 15,4\%, influenciado principalmente pelo acesso feminino efetivado na região Nordeste. A partir desses dados pode-se apontar para a continuidade das relações patriarcais na agricultura familiar brasileira e, de modo mais acentuado, no Estado de Santa Catarina, uma vez que o acesso à política de crédito rural pode significar relações familiares mais próximas da igualdade, o que significa que o Estado parece distante disso. Por isso, recomendamos que investigações mais profundas a esse respeito possam ser empreendidas por estudos que busquem esse objetivo, podendo contribuir para repensar as atuais linhas e regras de acesso a essa política. A exemplo, pode-se citar os estudos de Spanevello, Matte e Boscardin (2016), para o Rio Grande do Sul, e Brumer e Spanevello (2012), para a região Sul do Brasil, ilustrando a necessidade de ajustes ao crédito Pronaf Mulher, visto que ele nem sempre tem sido acessado para de fato atender a demandas de mulheres, como é seu real propósito.

A caracterização do acesso ao crédito por faixa etária no período 2013-2018 no Estado de Santa Catarina concentrou a maior parte de suas operações nas faixas entre 30 e 39 anos, 40 e 49 anos e 50 e 59 anos. Essas três faixas somaram juntas $74,8 \%$ dos contratos e $74,5 \%$ dos recursos. Já os contratantes com idade inferior a 30 anos significaram nesse período $11,4 \%$ das operações, enquanto os beneficiários acima de 60 anos representaram 13,8\% das operações do Pronaf em Santa Catarina entre 2013 e 2018. A distribuição por faixa etária pode ser considerada dentro da normalidade ao considerar o ciclo de vida e de produção no interior da agricultura familiar, contudo chama-se a atenção para o fato de que a linha alternativa do Pronaf Jovem está pouco desenvolvida e de certa maneira fragilizada ao considerar a realidade catarinense. 
O tipo do beneficiário predominante é "Produtor Rural" (pessoa física ou jurídica), agricultores com renda anual de até $\mathrm{R} \$ 115$ mil, responsáveis por $50,4 \%$ das operações. Isso significa que $49,4 \%$ não informaram o tipo de beneficiário, caindo em uma classificação genérica ou ainda não informada, inibindo entendimento mais claro sobre quem acessa o Programa e ainda prejudica proposições de melhorias na política pública.

A variável de estratificação dos contratos por faixa concentrou-se nas operações de até $\mathrm{R} \$ 20.000,00$, um total de $63,3 \%$ dos contratos e $25 \%$ do montante de recursos. A faixa de valores entre mais de $R \$ 20.000,00$ e até $R \$ 100.000,00$ significou $21,3 \%$ dos contratos e 43,1\% dos recursos. Já as transações do Pronaf acima de $\mathrm{R} \$ 100.000,00$ representaram apenas $0,2 \%$ dos contratos e $10,1 \%$ do montante dos recursos. Essas informações permitem apontar para a concentração da quantidade de contratos nas operações da faixa de valores mais baixos, até $\mathbf{2 0}$ mil reais. À medida que as faixas de valores vão crescendo ocorre o fenômeno inverso, a concentração se materializa no montante de recursos, constituindo assim, por mais esta variável, certos vícios do Programa em termos de democratização dos financiamentos.

Os dados permitem afirmar que a distribuição se dá em praticamente sua totalidade para pessoas físicas, em sua ampla maioria para agricultores do sexo masculino, principalmente acima de 39 anos de idade. Em torno de dois terços dos contratos realizados são de até $R \$ 20.000,00$, observando-se que tais operações equivalem apenas a um quarto do montante financeiro. Além disso, há um enquadramento genérico quanto ao tipo do beneficiário, o que impossibilita uma análise sobre os grupos no interior da agricultura familiar que acessam o crédito Pronaf em Santa Catarina.

\section{Evolução e Distribuição do Crédito do Pronaf no Estado}

Em relação às operações contratuais, no período de 1996 a 2018 o Estado de Santa Catarina efetivou o significativo montante de 2.525 .128 contratos de crédito rural por meio do Pronaf, cuja maior parte foi destinada à finalidade de custeio. Os contratos de custeio totalizaram no período 2.019.273, o que representa a expressiva marca de $80,0 \%$ em relação ao total de contratos realizados pelo Programa. Entre as explicações para esse expressivo percentual pode estar a garantia do seguro, acessado juntamente com o crédito custeio do Pronaf.

Os contratos de investimentos somaram 505.692 no período entre 1996 e 2018, o que representou $20 \%$ do total. Os contratos de industrialização ${ }^{5}$ foram registrados apenas nos anos de 2016, ${ }^{6} 2017$ e 2018 e totalizaram ao longo desses três anos o somatório de 133 acordos contratuais, que em termos percentuais ainda não expressa significância em termos de resultado.

$\mathrm{O}$ alto percentual destinado para a finalidade de custeio significa a dependência por parte dos agricultores no que tange à viabilização de suas atividades produtivas. Toledo (2009) classificou o Pronaf como "círculo vicioso". Já Delgado (1985 ) classifica

\footnotetext{
As finalidades do crédito para industrialização estão contidas no Art. 7ํ da Resolução 4.575 do Banco Central.

${ }^{6}$ Ano de início dessa modalidade de crédito.
} 
a entrada do crédito rural na agricultura como a efetiva penetração do capital no setor, embora esse fenômeno tenha ocorrido com maior abrangência no segmento familiar a partir do Pronaf.

Outros dois aspectos precisam ser destacados a partir dos dados ilustrados no Gráfico 1. O primeiro está relacionado ao considerável decréscimo no número de contratos na modalidade de custeio, com redução de 35,4\% no comparativo 1996/2018, passando de 98.204 para 63.409 contratos. O segundo aspecto reflete a baixa cobertura da modalidade entre os estabelecimentos familiares catarinenses, visto que o número de contratos representa em 2018 em torno de apenas um terço do total de propriedades do Estado enquadradas na Lei n. 11.326/2006. Esses aspectos, por si sós, já evidenciam certos "(des)caminhos" do Programa em Santa Catarina, pois há uma concentração dos contratos nas operações de custeio e redução importante no número de contratos totais, resultando em uma contemplação seletiva do Programa, sobretudo nas atividades primárias da agricultura.

Gráfico 1 - Número de contratos totais e de custeio efetivados via Pronaf por agricultores familiares em Santa Catarina, no período de 1996 a 2018

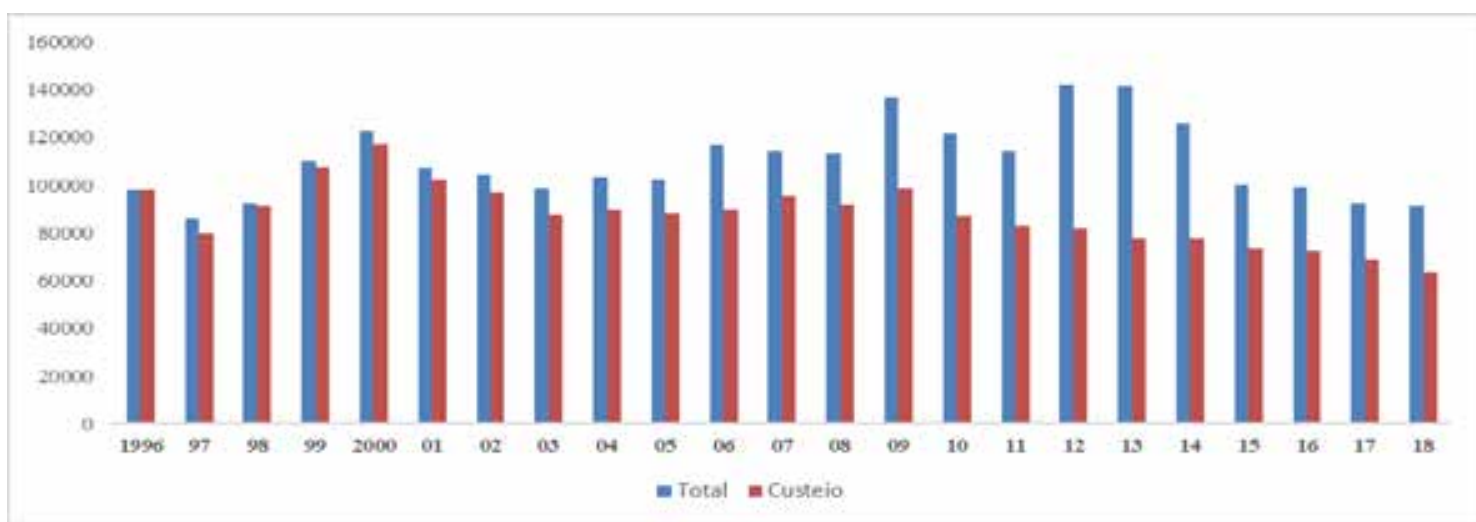

Fonte: Elaboração do primeiro autor com base em dados do Banco Central do Brasil (2018).

Em consequência desse movimento, percebe-se o incremento no número de contratos para a modalidade de investimento no Estado, mais acentuado a partir do ano de 2005 e principalmente desde a criação da linha de financiamento do Mais Alimentos em 2008. ${ }^{7}$ Em 2005 os contratos de investimento representaram 11,6\% em relação ao total, apresentando tendência de crescimento ao longo dos anos, com registro de $44,9 \% \mathrm{em}$ 2013 (maior percentual da série histórica) e de 30,2\% do total dos contratos em $2018 .{ }^{8}$

Esta evolução, de certa forma, impulsionou a ampliação da produção, da estrutura e, ao mesmo tempo, da modernização das propriedades vinculadas à agricultura familiar, especialmente dos agricultores mais capitalizados e integrados às cadeias produtivas do agronegócio. Essa modernização, entretanto, ocorreu de forma restrita no interior da agricultura familiar, fato este já demarcado significativamente na literatura brasileira (GAZOLLA; SCHNEIDER 2013; AQUINO; SCHNEIDER, 2010; 2015; CAZELLA et al., 2016).

\footnotetext{
7 O Pronaf Mais Alimentos destina recursos para investimentos em infraestrutura produtiva.

8 Comparado à evolução observada no país, podemos considerar tal evolução como restritiva, visto que ao final do ano de 2018 a modalidade de investimento em número de contratos do Pronaf representou 63,1\% no Brasil.
} 
Em relação aos demais Estados brasileiros, segundo os dados do Banco Central, Santa Catarina, ao longo desses 23 anos do Pronaf (1996-2018), posiciona-se como a quinta unidade da Federação com maior número de contratos do país, ficando atrás, em termos de contratos, apenas do Rio Grande do Sul, Bahia, Minas Gerais e Paraná, contudo até 1998 o Estado catarinense ocupou a segunda posição em termos de Brasil e, até 2003, a terceira quanto ao número de operações efetivadas.

No que tange à distribuição dos contratos totais (custeio, investimento e industrialização), na Figura 1 são ilustradas as mesorregiões do Estado de Santa Catarina, com respectivos valores para o total de contratos efetivados (em valor relativo), a taxa de crescimento no número de acessos ao Pronaf e o número total de contratos (em valor absoluto) para o período compreendido de 1996 a 2018.

Figura 1 - Total de contratos efetivados em valor relativo (primeiro valor), taxa de crescimento no número de acessos ao Pronaf (segundo valor) e número total de contratos em valor absoluto (terceiro valor) para o período de 1996 a 2018 nas mesorregiões do Estado de Santa Catarina

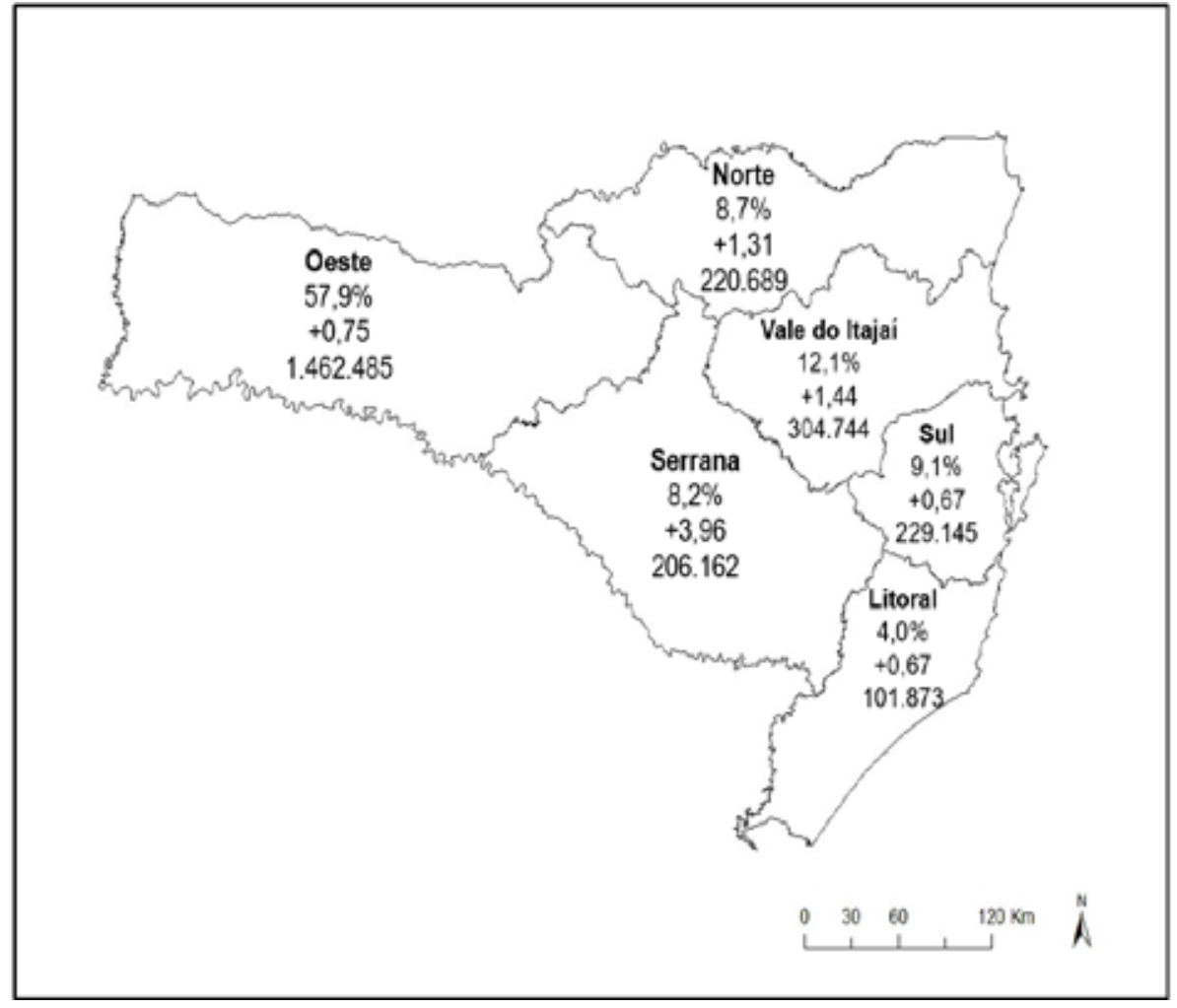

Fonte: Elaborada pelos autores.

Observa-se que entre as mesorregiões do Estado catarinense, a mesorregião Oeste é a que concentra o maior número de contratos, com percentual de $57,9 \%$ do total no período de 1996 a 2018, o que significa em termos absolutos o total de 1.462 .485 contratos. Essa concentração pode apontar algum grau de dependência da agricultura familiar regional em relação ao crédito rural, como condição para a viabilidade e permanência nas atividades produtivas, mas esse fator precisa ser investigado em estudos empíricos nessa mesorregião. Vale ressaltar que as atividades produtivas preponderantes nessa mesorregião estão diretamente ligadas aos sistemas integrados de criação de suínos e aves, que envolvem a contratação de recursos, especialmente para a construção de benfeitorias. 
O Vale do Itajaí é a segunda mesorregião com maior número de contratos efetivados, representando 12,1\% (304.744). Na sequência estão as regiões Sul, Norte, Serrana e Litoral com 9,1\% (229.145), 8,7\% (220.689), 8,2\% (206.162) e 4\% (101.873) contratos por mesorregião respectivamente. Essa condição de acesso, assim como citado anteriormente, também está associada à estrutura e às dinâmicas em que a agricultura familiar em cada uma das regiões está inserida.

No que se refere à expansão do Programa em cada uma das regiões, comparando os dados de 1996 com 2018 é possível identificar outro cenário, pois a mesorregião Serrana foi a que mais expandiu em relação ao número de contratos, com índice de 3,96 no comparativo entre 1996/2006. Na sequência, a mesorregião Litorânea registrou um índice de 2,69, e as regiões do Vale do Itajaí e Norte ficaram com índices de 1,44 e 1,31 respectivamente. Por fim, a mesorregião Oeste, com 0,75, e Sul, com índice de 0,67, apresentaram redução do Programa em termos de número de contratos.

Esses índices regionais demonstram a expansão do Pronaf no Estado em regiões que no início do Programa acessaram-no de forma tímida, bem como certo encolhimento nas regiões em que o acesso no ano de 1996 se apresentou de forma significativa. A redução do número de contratos, entretanto, é um fenômeno que vem ocorrendo em todos os Estados do país, especialmente a partir de 2015. Em outros termos, o Programa que se propõe ao fortalecimento da agricultura familiar cada vez mais registra seletividade em seu acesso, além de que, considerando o acesso de anos anteriores, muitos agricultores estão realizando o pagamento dos primeiros empréstimos antes de acumular novos.

Os dados revelam a redução em termos relativos da concentração dos contratos realizados na mesorregião Oeste, que passou de 70,6\% em 1996 para 57,0\% em 2018. Ainda se tratando da mesorregião Oeste, essa diminuição na participação dos contratos ocorre em detrimento do aumento no número de contratos para as demais regiões do Estado e da própria dinâmica do Pronaf. Sobre esse "enxugamento", entretanto, somente a mesorregião Oeste apresentou redução de aproximadamente 16 mil contratos, fato que demonstra claramente que o Programa ao longo dos anos perdeu fôlego em termos de número de contratos e agricultores atendidos. Isso porque, na sistemática do Programa, os agricultores familiares, para assegurar um mínimo de lucratividade, aceitam aumentar a carga de trabalho e a intensidade produtiva, tornando a desvantajosa a participação no Programa.

Por outro lado, tal redução pode ser explicada pela cautela dos agricultores familiares em quitarem seus empréstimos antes de iniciarem novos. Em alguma medida, esta pode ser uma importante pergunta de pesquisa para novos estudos, uma vez que os dados quantitativos não são suficientes para explicar essa mudança. Aliado a isso, levantamos como hipótese que essa redução pode ter relação com mudanças nas atividades produtivas em curso na mesorregião Oeste, o que mereceria investigação empírica e correlacional aos dados do Censo Agropecuário, recentemente disponibilizados.

Essa realidade corrobora as diretrizes iniciais do Pronaf estabelecidas no relatório da FAO/Incra (1994), em que o público preferencial para atendimento do Programa seriam os agricultores familiares consolidados e aqueles na fase de transição. Em outros termos, ao longo dos anos o Programa vai marginalizando o acesso e concentrando suas operações em contratos de maior volume de recurso financeiro. 
Assim como ocorre a prevalência do número de contratos de custeio no Estado de Santa Catarina (média do Estado no período: 81,9\%), em nenhuma mesorregião é constatado significativo descolamento de tal percentual, isso porque os percentuais situaram-se entre os limites de 80,6\% e 86,9\%. Em termos absolutos, considerando o histórico do Programa, destaca-se a mesorregião Oeste, que já no ano de 2015 ultrapassou a marca de 1 milhão de contratos de custeio, finalizando o ano de $2018 \mathrm{com} 1.152 .371$ de contratos efetivados, o que equivale a uma média de aproximadamente 64 mil contratos anuais. Com a disponibilização dos dados do Censo Agropecuário 2017, correlações podem ser realizadas para ampliar o escopo de compreensões em torno das mudanças no acesso à políticas de crédito.

Em contrapartida, o acesso ao crédito de investimento apresenta-se de forma modesta (comparativamente ao crédito de custeio) em todas as regiões quando observado o conjunto da série histórica. A partir de 2006, no entanto, a linha de crédito apresenta crescimento em relação ao número de contratos totais do Estado, chegando a seu ápice em 2014, quando atingiu 44,9\% do total. Tal evolução foi impulsionada principalmente a partir do Programa Mais Alimentos, que foi, majoritariamente, utilizado para a aquisição de maquinário agrícola, com destaque para a compra de tratores de pequeno porte. Outro aspecto desse incremento está associado aos constantes investimentos exigidos pelas atividades de pecuária (principalmente leiteira e de sistemas integrados com suínos e aves), tão presente no Estado de Santa Catarina, conforme ilustrado em estudo realizado por Fossá (2015).

O acesso ao crédito de investimento para o agricultor familiar pode significar o fortalecimento de suas ações como produtor, pois oportuniza condições para início e ampliação da produção, e consequentemente também fortalece suas relações com os atores e o mercado, os quais poderão interferir na gestão e nos modos de produção da propriedade (RAMBO, 2014). Nos termos de Cazella et al. (2016), o Pronaf, em sua trajetória, acaba por se distanciar dos grupos da agricultura familiar em situação de maior vulnerabilidade econômica e social. Na medida em que fomenta mais atividades integradas às grandes cadeias produtivas, o Programa acaba não apoiando suficientemente modos alternativos de agricultura, bem como agricultores familiares que atuam em mercados informais e para o autoconsumo.

Quanto aos recursos, em 1996 Santa Catarina contratou aproximadamente R\$ 520 milhões, enquanto em 2018 o valor foi de $R \$ 2,7$ bilhões, crescimento este que significa mais de cinco vezes ao valor contratado em 1996. Ao longo do Programa, o maior volume de recursos contratados foi no ano de 2014, quando o valor ultrapassou os $\mathrm{R} \$$ 3,6 bilhões. O volume de crédito contratado entre 2015 e 2018 no Estado foi inferior ao nível de 2014, principalmente pelo cenário econômico e político instável vivenciado no país e pela alteração (elevação) da taxa de juros do Programa nos últimos anos, e também pelo limite de crédito já acessado por muitas famílias. Em termos relativos, no Brasil os financiamentos cresceram 973,0\%, enquanto o Estado de Santa Catarina apresentou evolução de aproximadamente $534,0 \%$.

Em relação ao volume de recursos por finalidade (custeio, investimento e industrialização), assim como ocorre na perspectiva dos contratos, o crédito de custeio concentra a maior parcela dos recursos em Santa Catarina, destacando-se que no período entre 1996 e2018 essa linha de crédito (custeio) representa em média 62,5\% do to- 
tal dos financiamentos contratados no Estado catarinense. O crédito de investimento, todavia, vem ganhando espaço recentemente: especificamente nos últimos 12 anos (2007-2018) representou 43,3\% do total dos recursos acessados.

Em continuidade sobre a linha de crédito de investimento, esse incremento assume papel importante para a estrutura produtiva do segmento rural familiar catarinense, uma vez que consiste de linha de financiamento capaz de dinamizar a capacidade produtiva, bem como consequentemente promover melhoria nos indicadores de produtividade, por meio da compra e utilização de maquinários, estrutura e veículos com maior nível de tecnologia.

Tabela 1 - Montante de recursos financeiros acessados via Pronaf por finalidade contratados em Santa Catarina no período de 1996 a 2018

\begin{tabular}{|c|c|c|c|c|c|c|c|c|}
\hline Ano & Valor Custeio & $\%$ & $\begin{array}{c}\text { Valor } \\
\text { Investimento }\end{array}$ & $\%$ & $\begin{array}{c}\text { Valor } \\
\text { Industrialização } \\
\end{array}$ & $\%$ & Valor Total & $\%$ \\
\hline 1996 & 522.659 .952 & 99,9 & 494.395 & 0,1 & 0 & 0 & 523.154 .347 & 100,0 \\
\hline 1997 & 1.335 .324 .688 & 84,4 & 246.150 .560 & 15,6 & 0 & 0 & 1.581 .475 .248 & 100,0 \\
\hline 1998 & 719.712 .991 & 94,1 & 45.254 .095 & 5,9 & 0 & 0 & 764.967 .086 & 100,0 \\
\hline 1999 & 810.562 .637 & 93,5 & 55.979 .388 & 6,5 & 0 & 0 & 866.542 .024 & 100,0 \\
\hline 2000 & 864.204 .118 & 91,8 & 77.456 .736 & 8,2 & 0 & 0 & 941.660 .854 & 100,0 \\
\hline 2001 & 795.216 .552 & 85,5 & 135.094 .857 & 14,5 & 0 & 0 & 930.311 .408 & 100,0 \\
\hline 2002 & 877.760 .030 & 85,5 & 149.117 .703 & 14,5 & 0 & 0 & 1.026 .877 .733 & 100,0 \\
\hline 2003 & 624.550 .564 & 71,7 & 246.659 .055 & 28,3 & 0 & 0 & 871.209 .619 & 100,0 \\
\hline 2004 & 720.698 .437 & 78,4 & 198.979.981 & 21,6 & 0 & 0 & 919.678 .418 & 100,0 \\
\hline 2005 & 860.285 .337 & 73,6 & 308.065 .298 & 26,4 & 0 & 0 & 1.168 .350 .636 & 100,0 \\
\hline 2006 & 914.961 .669 & 71,5 & 364.928 .087 & 28,5 & 0 & 0 & 1.279 .889 .757 & 100,0 \\
\hline 2007 & 1.071 .798 .221 & 74,3 & 370.272 .357 & 25,7 & 0 & 0 & 1.442 .070 .578 & 100,0 \\
\hline 2008 & 1.260 .258 .506 & 65,5 & 664.084 .684 & 34,5 & 0 & 0 & 1.924 .343 .190 & 100,0 \\
\hline 2009 & 1.337 .049 .904 & 52,5 & 1.211 .136 .463 & 47,5 & 0 & 0 & 2.548 .186 .367 & 100,0 \\
\hline 2010 & 1.357 .977 .766 & 52,8 & 1.211 .671 .023 & 47,2 & 0 & 0 & 2.569 .648 .789 & 100,0 \\
\hline 2011 & 1.382 .227 .278 & 53,0 & 1.225 .917 .573 & 47,0 & 0 & 0 & 2.608 .144 .851 & 100,0 \\
\hline 2012 & 1.502 .694 .131 & 53,6 & 1.302 .725 .221 & 46,4 & 0 & 0 & 2.805 .419 .352 & 100,0 \\
\hline 2013 & 1.588 .816 .297 & 49,3 & 1.637 .174 .244 & 50,7 & 0 & 0 & 3.225 .990 .541 & 100,0 \\
\hline 2014 & 1.656 .672 .500 & 45,5 & 1.983 .515 .639 & 54,5 & 0 & 0 & 3.640 .188 .139 & 100,0 \\
\hline 2015 & 1.666 .571 .480 & 62,3 & 1.008 .612 .082 & 37,7 & 0 & 0 & 2.675 .183 .562 & 100,0 \\
\hline 2016 & 1.695 .264 .520 & 58,1 & 1.099 .337 .052 & 37,7 & 124.372 .110 & 4,3 & 2.918 .973 .682 & 100,0 \\
\hline 2017 & 1.802 .530 .147 & 61,6 & 1.036 .155 .909 & 35,4 & 89.831 .885 & 3,1 & 2.928 .517 .940 & 100,0 \\
\hline 2018 & 1.765 .396 .364 & 54,5 & 1.318 .740 .923 & 40,7 & 154.457 .300 & 4,8 & 3.238 .594 .587 & 100,0 \\
\hline
\end{tabular}

Fonte: Elaborado pelos autores com base em dados do Banco Central do Brasil (2018).

Além disso, tais investimentos possibilitam a melhoria das condições de trabalho por meio da utilização de novos métodos laborais, e ainda supre a carência de mão de obra, cada vez mais escassa no meio rural do Estado. Por outro lado, também exclui e endivida atores, visto que aquele agricultor que não consegue êxito financeiro na aplicação do crédito rural chega, em alguns casos, a comprometer o patrimônio familiar para saldar seus compromissos. Além disso, há um conjunto significativo de agricultores que não se sentem seguros ao realizar financiamentos de valores elevados.

Em continuidade, a linha de financiamento de investimento caracteriza-se por não limitar seus efeitos apenas no ano de contratação, mas também gera efeitos ao longo dos anos seguintes à sua contratação. Em outros termos, o investimento dilui-se e gera resultados na propriedade no longo prazo. Em Santa Catarina, a linha de crédito de investimentos registrou crescimento de mais de $662,0 \%$ nos últimos 15 anos do Programa (2004-2018), passando de $R \$ 198.979 .981$ em 2004 para $R \$ 1.318 .740 .923$ em 2018. Esse valor é expressivamente maior do que o registrado em todo o país, que no mesmo período evoluiu aproximadamente $372,0 \%$, alterando seu valor de $\mathrm{R} \$ 4.951 .193 .996 \mathrm{em}$ 2004 para 11.388.953.648 no ano de 2018. 
Um dos aspectos que pode explicar esse expressivo crescimento em Santa Catarina é o perfil da agricultura familiar que acessa o Pronaf no Estado, que se caracteriza como um conjunto de agricultores mais capitalizados, e, em consequência, se utilizaram em maior grau dos recursos de investimentos do que a maioria dos Estados da Federação no âmbito da agricultura familiar. Isso demonstra o potencial da agricultura familiar do Estado tanto em termos sociais como econômicos, conforme demonstrado por Mattei (2010).

A partir disso, naturalmente o valor médio dos contratos tiveram significativa elevação. O crescimento anual do valor médio, cujo percentual foi analisado ao longo do período (1996-2018), foi de 13,3\%, passando de $\mathrm{R} \$ 5.276$ em 1996 para $\mathrm{R} \$ 30.436$ no ano de 2018.

A partir de 2004, contudo, registra-se significativa elevação dos valores médios por contrato, incidindo claramente em uma necessidade crescente de crédito. Entre as modalidades de financiamento, o valor médio dos contratos teve um aumento significativo no período em Santa Catarina, pois, na modalidade de crédito para o custeio, o índice apresentou de certa forma um crescimento linear ao longo desse intervalo de tempo. No comparativo entre o início do Programa e o ano de 2018 registraram-se em 1996 o valor de $R \$ 5.322$, e em 2018 o valor $R \$ 27.841$. 111. Na linha de financiamento para investimento, o valor médio passou de $R \$ 23.543$ em 1996 para $R \$ 48.108$ em 2018, mais que dobrando de valor ao longo da existência do Programa.

Os valores médios são fundamentais para entender a dinâmica da evolução do acesso ao crédito, que nesse caso aponta, para a realidade de Santa Catarina, a necessidade crescente e constante de maiores montantes de recursos para financiamento da produção por parte do agricultor familiar. Essa condição já foi demonstrada na própria percepção dos agricultores em pesquisa realizada por Winckler e Renk (2013). Em termos regionais, quanto ao volume de recursos financeiros contratados, a mesorregião Oeste é a responsável pela contratação do maior volume, que ao longo da série histórica representou 55,5\% do total. Em 2018, por exemplo, dos $\mathrm{R} \$ 3,2$ bilhões contratados pelo Estado, R\$1,9 bilhão foi pelos agricultores familiares da mesorregião Oeste, representando nesse ano 59,3\%.

Ao considerar a série histórica, o valor contratado apenas no Oeste do Estado ultrapassa os $\mathrm{R} \$ 24$ bilhões. A mesorregião do Vale do Itajaí se posiciona na sequência em termos de volume contratado, registrando no período analisado a quantia de $\mathrm{R} \$ 5,9$ bilhões, o que representa 13,9\% em relação ao total. A mesorregião Sul é a terceira que mais contratou entre 1996-2018, com um volume de $\mathrm{R} \$ 4,4$ bilhões, correspondendo a $10,3 \%$ do total. 
Tabela 2 - Evolução de recursos financeiros, contratos, valor médio dos contratos, acessados via Pronaf por agricultores familiares no Brasil e em Santa Catarina, no período de 1996 a 2018

\begin{tabular}{|c|c|c|c|c|c|c|c|c|}
\hline & \multicolumn{4}{|c|}{ Brasil } & \multicolumn{4}{|c|}{ Santa Catarina } \\
\hline & Recursos & Contratos & $\begin{array}{l}\text { Valor } \\
\text { médio }\end{array}$ & $\begin{array}{c}\text { Evolução } \\
(\%) \text { Anual }\end{array}$ & Recursos & Contratos & $\begin{array}{l}\text { Valor } \\
\text { médio }\end{array}$ & $\begin{array}{c}\text { Evolução } \\
\text { (\%) Anual }\end{array}$ \\
\hline 1996 & $\mathrm{R} \$ 2.066 .308 .282$ & 306.786 & $\mathrm{R} \$ 6.735$ & -- & $\mathrm{R} \$ 518.087 .409$ & 98.200 & $\mathrm{R} \$ 5.276$ & -- \\
\hline 1997 & $\mathrm{R} \$ 6.787 .805 .683$ & 477.718 & $\mathrm{R} \$ 14.209$ & 111,0 & $\mathrm{R} \$ 1.320 .428 .372$ & 85.724 & $\mathrm{R} \$ 15.403$ & 192,0 \\
\hline 1998 & $\mathrm{R} \$ 4.784 .215 .184$ & 636.794 & $\mathrm{R} \$ 7.513$ & $-47,1$ & $\mathrm{R} \$ 764.917 .297$ & 92.666 & $\mathrm{R} \$ 8.255$ & $-46,4$ \\
\hline 1999 & $\mathrm{R} \$ 5.830 .931 .978$ & 791.677 & $\mathrm{R} \$ 7.365$ & $-2,0$ & $\mathrm{R} \$ 865.969 .083$ & 110.084 & $\mathrm{R} \$ 7.866$ & $-4,7$ \\
\hline 2000 & $\mathrm{R} \$ 5.813 .139 .011$ & 834.049 & $\mathrm{R} \$ 6.970$ & $-5,4$ & $\mathrm{R} \$ 908.529 .201$ & 122.987 & $\mathrm{R} \$ 7.387$ & $-6,1$ \\
\hline 2001 & $\mathrm{R} \$ 6.296 .804 .592$ & 800.653 & $\mathrm{R} \$ 7.865$ & 12,8 & $\mathrm{R} \$ 929.522 .001$ & 107.188 & $\mathrm{R} \$ 8.672$ & 17,4 \\
\hline 2002 & $\mathrm{R} \$ 6.950 .412 .909$ & 829.433 & $\mathrm{R} \$ 8.380$ & 6,5 & $\mathrm{R} \$ 1.026 .006 .384$ & 104.302 & $\mathrm{R} \$ 9.837$ & 13,4 \\
\hline 2003 & $\mathrm{R} \$ 7.103 .029 .424$ & 1.003 .837 & $\mathrm{R} \$ 7.076$ & $-15,6$ & $\mathrm{R} \$ 868.240 .384$ & 98.518 & $\mathrm{R} \$ 8.813$ & $-10,4$ \\
\hline 2004 & $\mathrm{R} \$ 9.300 .004 .694$ & 1.345 .713 & $\mathrm{R} \$ 6.911$ & $-2,3$ & $\mathrm{R} \$ 1.100 .047 .300$ & 103.551 & $\mathrm{R} \$ 10.623$ & 20,5 \\
\hline 2005 & $\mathrm{R} \$ 11.670 .826 .324$ & 2.208 .198 & $\mathrm{R} \$ 5.285$ & $-23,5$ & $\mathrm{R} \$ 1.276 .135 .357$ & 102.654 & $\mathrm{R} \$ 12.431$ & 17,0 \\
\hline 2006 & $\mathrm{R} \$ 14.060 .007 .570$ & 2.551 .497 & $\mathrm{R} \$ 5.510$ & 4,3 & $\mathrm{R} \$ 1.473 .390 .853$ & 116.674 & $\mathrm{R} \$ 12.628$ & 1,6 \\
\hline 2007 & $\mathrm{R} \$ 13.290 .980 .489$ & 1.923 .317 & $\mathrm{R} \$ 6.910$ & 25,4 & $\mathrm{R} \$ 1.476 .286 .545$ & 114.078 & $\mathrm{R} \$ 12.941$ & 2,5 \\
\hline 2008 & $\mathrm{R} \$ 15.183 .943 .001$ & 1.550 .749 & $\mathrm{R} \$ 9.791$ & 41,7 & $\mathrm{R} \$ 1.874 .602 .638$ & 113.361 & $\mathrm{R} \$ 16.537$ & 27,8 \\
\hline 2009 & $\mathrm{R} \$ 18.883 .624 .706$ & 1.704 .947 & $\mathrm{R} \$ 11.076$ & 13,1 & $\mathrm{R} \$ 2.488 .190 .656$ & 136.556 & $\mathrm{R} \$ 18.221$ & 10,2 \\
\hline 2010 & $\mathrm{R} \$ 18.954 .856 .218$ & 1.585 .486 & $\mathrm{R} \$ 11.955$ & 7,9 & $\mathrm{R} \$ 2.515 .974 .943$ & 121.278 & $\mathrm{R} \$ 20.746$ & 13,9 \\
\hline 2011 & $\mathrm{R} \$ 19.831 .843 .325$ & 1.539 .901 & $\mathrm{R} \$ 12.879$ & 7,7 & $\mathrm{R} \$ 2.605 .962 .768$ & 114.506 & $\mathrm{R} \$ 22.758$ & 9,7 \\
\hline 2012 & $\mathrm{R} \$ 22.963 .107 .161$ & 1.823 .210 & $\mathrm{R} \$ 12.595$ & $-2,2$ & $\mathrm{R} \$ 2.805 .419 .352$ & 142.301 & $\mathrm{R} \$ 19.715$ & $-13,4$ \\
\hline 2013 & $\mathrm{R} \$ 26.581 .720 .069$ & 2.004 .121 & $\mathrm{R} \$ 13.264$ & 5,3 & $\mathrm{R} \$ 3.225 .990 .541$ & 141.251 & $\mathrm{R} \$ 22.839$ & 15,8 \\
\hline 2014 & $\mathrm{R} \$ 30.927 .559 .815$ & 1.825 .489 & $\mathrm{R} \$ 16.942$ & 27,7 & $\mathrm{R} \$ 3.640 .188 .139$ & 125.612 & $\mathrm{R} \$ 28.980$ & 26,9 \\
\hline 2015 & $\mathrm{R} \$ 24.491 .545 .245$ & 1.705 .731 & $\mathrm{R} \$ 14.358$ & $-15,3$ & $\mathrm{R} \$ 2.675 .183 .562$ & 100.117 & $\mathrm{R} \$ 26.721$ & $-7,8$ \\
\hline 2016 & $\mathrm{R} \$ 23.749 .352 .526$ & 1.615 .291 & $\mathrm{R} \$ 14.703$ & 2,4 & $\mathrm{R} \$ 2.866 .243 .466$ & 99.167 & $\mathrm{R} \$ 28.903$ & 8,2 \\
\hline 2017 & $\mathrm{R} \$ 21.621 .694 .817$ & 1.281 .180 & $\mathrm{R} \$ 16.876$ & 14,8 & $\mathrm{R} \$ 2.723 .776 .922$ & 92.379 & $\mathrm{R} \$ 29.485$ & 2,0 \\
\hline 2018 & $\mathrm{R} \$ 20.108 .274 .642$ & 1.126 .366 & $\mathrm{R} \$ 17.852$ & 5,8 & $\mathrm{R} \$ 2.766 .195 .656$ & 90.887 & $\mathrm{R} \$ 30.436$ & 3,2 \\
\hline Total & R\$ 337.251.987.664 & R\$ 31.472.143 & Média & 7,9 & R\$ 42.715.288.828 & R\$ 2.534.041 & Média & 13,3 \\
\hline
\end{tabular}

Fonte: Elaborado pelos autores com base em dados do Banco Central do Brasil (2018).

Em relação ao Pronaf Jovem e Pronaf Mulher, o desempenho também foi pífio, visto que entre 2013 e 2018 foram realizados somente 246 contratos, destes 14 do Pronaf Jovem e 232 do Pronaf Mulher. No que se refere ao montante acessado por essas duas linhas de crédito, este circulou em termos nominais no valor aproximado de $\mathrm{R} \$ 7,9$ milhões no período analisado. O resultado aqui também se aproxima da realidade dos demais Estados da Federação, nos quais esses públicos de fato têm apresentado significativas dificuldades para acesso ao Programa. Na visão de Spanevello, Matte e Boscardin (2016), é fundamental uma nova reorganização no Pronaf com o intuito de garantir a públicos, como os jovens e as mulheres, o devido acesso ao Programa.

Quanto às linhas "verdes" (Pronaf Agroecologia, Pronaf Eco, Pronaf Floresta) destinadas à produção de forma sustentável do ponto de vista ambiental, os resultados foram insignificantes quando comparados às linhas de crédito tradicionais do Programa, pois os dados do Bacen apontam para apenas 1.149 operações contratuais entre 2013 e 2018 no Estado de Santa Catarina. Em valores nominais, foram acessados apenas $\mathrm{R} \$ 57$ milhões no somatório das três referidas linhas de crédito. Esses resultados assemelham-se aos registrados em nível de país e, por sua vez, reforçam as fragilidades dessas linhas de financiamento no âmbito do Pronaf (AQUINO; GAZOLLA; SCHNEIDER, 2017). 


\section{As Finalidades do Crédito do Pronaf em Santa Catarina}

A partir desta análise do acesso ao Pronaf em Santa Catarina em termos de contratos, recursos, modalidade e distribuição regional pelos agricultores familiares, outro importante aspecto desse acesso é a finalidade desses contratos, ou seja, a quais culturas e atividades estão destinando os recursos do crédito Pronaf em Santa Catarina, como apontam os trabalhos de Gazolla e Schneider (2013); Aquino e Schneider (2015) e Cazella et al. (2016), que questionam especialmente a concentração dos recursos em pouca diversidade de culturas e atividades.

A visão por produto, ${ }^{9}$ dados relativos ao Pronaf, compreenderá a análise no período entre os anos 2000 e 2018 conforme a disponibilidade de dados do Banco Central do Brasil. Tais informações, contudo, estão dispostas ao longo da série histórica de duas formas diferentes: a primeira compreende de 2000 a 2012, por meio do Anuário Estatístico do Crédito Rural, e a segunda, de 2013 a 2018, com os dados dispostos na Matriz de Dados do Crédito Rural. Tal observação faz-se necessária devido à significativa divergência existente entre tais relatórios no que se refere à sua estrutura e agrupamento de dados, o que, consequentemente, nos exige construir dois momentos distintos de análise quanto aos financiamentos por produto.

Em relação aos contratos de custeio das atividades de pecuária, entre os anos de 2000 e 2012 foram realizadas 101.252 operações do Pronaf em Santa Catarina, significando $8,3 \%$ do total de contratos destinados ao custeio. Entre tal finalidade, a compra de animais ${ }^{10}$ concentrou expressiva parcela tanto em número de contratos como de recursos. Isso porque somente essa rubrica significou $83,3 \%$ dos contratos e $88,3 \%$ do total dos recursos das operações de custeio pecuário. No período entre 2013 e 2018 foram registradas 162.381 operações, das quais 90,8\% foram exclusivamente para aquisição de bovinos, que pode ser para a pecuária leiteira ou de corte, o que representou $81,9 \%$ do montante de recursos contratados para o custeio pecuário. Diferente dessa realidade, Matte e Waquil (2018), ao analisarem situações de vulnerabilidade na pecuária de corte no Sul do Rio Grande do Sul, apontam que no caso da pecuária de corte naquele Estado, o acesso ao crédito é menor e representa uma situação de vulnerabilidade. Isso nos conduz à hipótese de que aspectos culturais tem signficativa influência sobre o uso de políticas de crédito rural. Por sua vez, a finalidade de crédito para aquisição de suínos em Santa Catarina representou 2,6\% dos contratos e 3,8\% do montante de recursos, e a avicultura representou apenas $2,1 \%$ dos contratos e $1,9 \%$ dos recursos.

Esses percentuais podem chamar a atenção de um leitor mais distante da realidade em relação à baixa participação dos recursos e dos contratos acessados pela avicultura e também pela suinocultura. O Estado de Santa Catarina coloca-se como um dos principais produtores tanto de suínos como de aves do país e tais resultados podem ser explicados pelo fato de que os custos de tais atividades ocorrem por conta das agroindústrias, principalmente por meio do modelo de integração. Em continuidade, os altos valores da bovinocultura podem ser explicados pelo significativo tamanho da

\footnotetext{
9 Categoria de filtro de dados estabelecida pelo Banco Central para análise por tipo de produto.

${ }^{10}$ Apesar de o crédito de custeio não permitir a compra de animais, o registro ocorre nos dados oficiais.
} 
cadeia produtiva catarinense, especialmente em relação à bovinocultura leiteira. Tais estatísticas, contudo, colocam em destaque o caráter centralizador do Pronaf em torno de alguns tipos de produção, fato este evidenciado por meio dos dados que confirmam tal realidade também no território catarinense.

Em relação aos contratos de pecuária com a finalidade de investimento, tal linha de financiamento alcançou no período compreendido entre os anos 2000 e 2012 um total de 150.611 contratos. Os investimentos em aquisição de animais, máquinas e equipamentos e melhoramento das explorações somam juntos o percentual de $85,1 \%$ dos contratos e de $85,4 \%$ do montante de recursos contratados pelo Estado catarinense entre esses anos. Nesse período as operações de aquisição de animais individualmente representam a maior finalidade tanto de contratos como de valores aplicados, com $37,3 \%$ e 35,1\% respectivamente. A dinâmica ocorrida nos investimentos pecuários entre 2013 e 2018 segue a mesma lógica apresentada no período anterior, pois somente a aquisição de bovinos representou $34,0 \%$ dos contratos e $38,3 \%$ dos recursos financeiros.

As máquinas e equipamentos representaram, entre 2013 e 2018, 20,9\% dos contratos e $23,9 \%$ do montante financeiro. As operações do Pronaf no Estado (investimento na pecuária) também se colocam como significativas entre 2013 e 2018 em relação à estrutura física das propriedades. Estas alcançaram 9,1\% dos contratos e 17,5\% dos recursos em Santa Catarina. Os contratos com a finalidade de aquisição de veículos (inclusive tratores) registrou no período analisado $6,4 \%$ dos contratos e $13,5 \%$ do montante financeiro em relação aos contratos de investimento na pecuária efetivados por agricultores familiares catarinenses.

Os contratos para custeio agrícola somaram o total de 1.117.992, número que representa $74,4 \%$ do total geral de contratos realizados em Santa Catarina no período entre 2000 e 2012. É um valor expressivo, visto que os contratos específicos para aplicação em lavouras totalizaram 968.378 operações, o que representa $86,6 \%$ do total geral do Estado. Em relação aos financiamentos para a lavoura, a concentração em torno da cultura do milho nos chama a atenção, pois somente esta representa 59,3\% (do total de contratos de custeio agrícola).

Entre 2013 e 2018 foram efetivados em Santa Catarina 271.151 contratos de custeio agrícola, distribuídos em 91 produtos/culturas diferentes, contudo a maior parte dos contratos e recursos são destinados à produção de commodities, como o arroz, cebola, milho e soja. Estas quatro culturas somadas acumularam no período de 2013 a 2018 o expressivo percentual de 79,8\% dos contratos e 77,5\% em relação aos recursos, assinalando, em uma análise prévia, o caráter de concentração produtiva também estabelecido no âmbito de Santa Catarina.

É necessário registrar também o significativo aumento das operações do Pronaf contratadas exclusivamente para a soja em relação ao período de 2000-2012, o qual passou de $3,2 \%$ dos contratos e $4,1 \%$ dos recursos no primeiro período analisado para $14,2 \%$ dos contratos e 15,9\% dos recursos nos últimos 6 anos (2013-2018). De certo modo, podemos verificar em Santa Catarina, reservadas as proporções, significativo crescimento da cultura da soja, fenômeno este em ampla expansão em todo o país, como no Estado do Rio Grande do Sul e na região conhecida como "Matopiba" (AQUINO; SCHNEIDER, 2010; FAVARETO et al., 2019). Esses resultados corroboram as análises apresentadas por Vennet, Schneider e Dessein (2016), que apontam que a soja, diferen- 
temente do que se pensa, tem sido desenvolvida em grandes proporções pela agricultura familiar, e não apenas pelo agronegócio. No caso do milho, o significativo valor pode ser explicado pela relação da cultura com a pecuária, e o da soja, pelo crescimento do mercado.

No que se refere ao investimento agrícola, foram registrados no período entre 2000 e 2012 o total de 131.840 contratos, valor inferior aos contratos de investimento em pecuária, que foi de 150.611 considerando o mesmo período. As operações da linha de financiamento do investimento agrícola concentraram-se em mais de 50\% para aquisição de máquinas e implementos agrícolas, o que, em números absolutos, significou 68.516 contratos e, em valores nominais, o montante de $\mathrm{R} \$ 2,6$ bilhões entre 2000 e 2012. Em termos relativos, as máquinas e equipamentos representaram $52,0 \%$ dos contratos e $65,3 \%$ do montante dos recursos totais para essa modalidade de financiamento. Os financiamentos em melhoria das explorações também se destacam, pois contemplaram no período em análise $19,6 \%$ dos contratos e $12,4 \%$ dos recursos.

Em relação ao período mais recente, compreendido entre 2013 e 2018, a dinâmica anterior persiste, entretanto, de certa forma mais acentuada. Isso porque, dos 105.365 contratos efetivados, somente o financiamento para máquinas e equipamentos registrou um total de $62.292(59,1 \%)$ operações contratuais. O montante financeiro representou $67,5 \%$ do total de financiamentos acessados via modalidade de investimento agrícola. Outro aspecto que assume importância em termos de acesso ao Pronaf Investimento Agrícola é o da infraestrutura física, modalidade de financiamento que apresentou no Estado de Santa Catarina entre 2013 e 2018 a marca de 9,5\% em contratos e de $10,6 \%$ em recursos financeiros.

Em essência, o Pronaf vem significando o reconhecimento e o apoio à agricultura familiar no Brasil e em Santa Catarina por parte do governo federal. Isso significa que os recursos disponibilizados permitiram, em certa medida, modernizar o aparato produtivo, ampliar a capacidade produtiva e possibilitar novas relações e usos da mão de obra na propriedade. Essa política, portanto, significou, para a realidade catarinense, a continuidade de famílias de agricultores familiares no espaço rural, produzindo e vivendo a partir dos estímulos do programa.

Por outro lado, há fragilidades nessa política, conforme ilustrado em alguns estudos, como os trabalhos de Toledo (2009) e de Gazolla e Schneider (2013), que trataram sobre o Pronaf no Estado do Rio Grande do Sul. No caso de Santa Catarina, a partir dos dados aqui analisados, as principais fragilidades foram: i) concentração produtiva em culturas e atividades relacionadas a commodities; ii) redução do número de contratos e consequentemente diminuição da cobertura do Programa; iii) aumento significativo do valor médio financiado, explicitando a possibilidade de dependência financeira do programa; iv) frágil desempenho das linhas alternativas do Programa que visam a modelos de produção sustentáveis do ponto de vista ambiental e v) frágil desempenho das linhas alternativas do Programa que buscam a valorização de públicos específicos da agricultura familiar, como jovens e mulheres.

Por fim, registramos que nesta seção foram apresentados os principais indicadores de acesso dos agricultores familiares catarinenses ao Pronaf. Tais elementos demonstram a realidade aprofundada em relação à dinâmica do acesso ao Pronaf em 
Santa Catarina. Ao apurar os dados completos da série histórica (1996-2018) é possível identificar uma visão holística dos principais indicadores ao longo do tempo, bem como tais dados contribuem para a compreensão das transformações ocorridas.

Essas informações revelam o modo como se dá o acesso à política pública em questão, bem como seus resultados, e refletem toda a dinamicidade de uma categoria social em um dos Estados brasileiros com maior acesso ao Programa desde sua criação. Para além disso, apontam as contradições do Pronaf como política pública de fortalecimento da agricultura familiar também para a realidade catarinense. Conforme analisado, a distribuição do crédito Pronaf em Santa Catarina seguiu o caminho percorrido pelo país, especialmente no plano econômico, pelo boom das commodities e pela integração da agricultura familiar com a agroindústria. Em consequência disso, o Programa concentra o financiamento em poucas culturas, replicando na agricultura familiar catarinense o modelo de produção utilizado na forma empresarial/patronal.

\section{CONSIDERAÇÕES FINAIS}

Esta pesquisa, ao se propor analisar o acesso e distribuição do crédito Pronaf no Estado de Santa Catarina, investiga uma temática importante para o segmento da agricultura familiar. O Pronaf e sua trajetória no Estado colocam-se em uma relação ambígua, pois, ao mesmo tempo que são possíveis considerações positivas, é possível enumerar fragilidades que não foram superadas até aqui em sua trajetória.

Os dados sobre o acesso e distribuição do Pronaf em Santa Catarina revelam um perfil de produção na agricultura familiar fortemente inserido nas cadeias produtivas do agronegócio. Essa condição resulta em significativa intensidade do trabalho, tornando as unidades familiares altamente eficientes em termos de produtividade, ao mesmo tempo que reforça um modelo de agricultura dependente dos recursos externos, especialmente insumos, como fertilizantes e produtos de nutrição animal.

Ainda sobre o acesso e a distribuição dos recursos do Pronaf, estes se expandiram em Santa Catarina de forma considerável, porém a cobertura do Programa em termos de contratos apresentou significativa redução, especialmente a partir do ano de 2014, como consequência da crise econômica e política pela qual passou o país entre os anos de 2015 e 2016, que acabou também repercutindo no Estado catarinense. De fato, contudo, o que se cristaliza na trajetória do Pronaf em Santa Catarina, por meio da expansão dos recursos tanto para custeio como para investimento, é a concentração desses recursos no perfil de agricultores familiares mais "consolidados" que, por meio de financiamentos cada vez maiores encontram soluções para continuidade e sobrevivência de suas propriedades.

Na análise do programa em Santa Catarina, a qual segue a dinâmica nacional, conforme já demonstramos, um número cada vez menor de agricultores familiares catarinenses está sendo responsável por um volume maior de recursos, logicamente impulsionando para cima o valor médio dos contratos na série histórica. Essa realidade social pode ser diagnosticada por duas óticas distintas, porém relacionadas à mesma causa. $A$ primeira diz respeito à própria "seleção do mercado", que induz, nos termos de Toledo (2009), um "círculo vicioso" em torno do Pronaf, exigindo, em nome dos ganhos de escala e dos reajustes produtivos, cada vez maiores níveis de investimento por parte dos agricultores familiares. 
A segunda ótica está ligada à exclusão produtiva, abandono das atividades e diminuição demográfica no interior do segmento da agricultura familiar do Estado de Santa Catarina. A exclusão produtiva a que nos referimos significa a ruptura da integração às cadeias produtivas do agronegócio por falta de capacidade creditícia e/ou opção de não endividamento em longo prazo e comprometimento do patrimônio familiar. $\mathrm{O}$ abandono das atividades coloca-se como causa da exclusão, mas nos referimos àquele conjunto de agricultores familiares que retornam à condição de produção para subsistência e que completam seus rendimentos com atividades fora da propriedade e com aposentadorias, arrendamentos e outras rendas. A diminuição demográfica, acompanhada do envelhecimento de parte significativa da agricultura familiar catarinense, se constitui, em conjunto com os demais aspectos levantados, um elemento que pode explicar a redução do número de contratos.

Outra questão exposta ao longo deste estudo é a concentração do financiamento do Pronaf em poucas culturas. Esse é o ponto nevrálgico do Programa já discutido para outras realidades nos estudos, mas que se apresenta também no acesso e distribuição do crédito Pronaf em Santa Catarina. Conforme demonstramos, aproximadamente $80 \%$ do crédito custeio acessado pelo Estado nos últimos anos foram direcionados apenas para quatro culturas (soja, milho, arroz e cebola).

Essa condição nos faz importar para a realidade de nosso estudo o questionamento de Gazolla e Schneider (2013) - "Qual fortalecimento?" - sobre as contribuições do Pronaf para o conjunto da agricultura familiar catarinense, pois tais culturas remetem às cadeias do agronegócio, que por sua vez exigem especialização produtiva, monocultura e, como consequência, interferem em uma das características-chave da agricultura familiar no Estado, que é a questão da diversificação produtiva. A canalização dos recursos do Pronaf às commodities seria, nas palavras de Aquino e Schneider (2010), um "(Des)caminho" do programa também na realidade de Santa Catarina?" De todo modo, os dados apresentados em relação ao Estado catarinense coadunam com a afirmação de Cazella et. al (2016), que consideram o Pronaf um programa financiador do "agronegocinho".

Nessa esteira, um terceiro aspecto se sobressai em relação à trajetória do Pronaf no Estado de Santa Catarina: sua incapacidade de fortalecimento das linhas alternativas do Programa, tanto as linhas "verdes", com objetivo de financiamento de modelos sustentáveis, como as linhas para públicos específicos, como o Pronaf Jovem e o Pronaf Mulher. Essa fragilidade em torno dessas linhas alternativas evidencia que as ações do Estado, das instituições (bancárias e movimentos sociais) e dos próprios agricultores familiares foram insuficientes, em termos de organização, para articulação e capilaridade do acesso e distribuição dessas linhas alternativas no Estado de Santa Catarina. As dificuldades para acesso nessas linhas são inúmeras e comparativamente mais burocráticas que as tradicionais. Um exemplo que pode resumir tal situação são as palavras de um agente bancário executor do Pronaf: "É muito mais fácil fazer o tradicional" (FOSSÁ, et. al., 2018).

Ao efetivar reflexões sobre o acesso e a distribuição do crédito Pronaf no Estado de Santa Catarina, constatou-se que o Programa, através dos anos, vem ganhando sua importância em termos de financiamento das atividades produtivas da agricultura familiar. Para além disso, os dados nos permitem afirmar que o Programa contribuiu e ain- 
da continua contribuindo para o processo de modernização e ampliação da capacidade produtiva da agricultura familiar do Estado. É notório, entretanto, que esse processo de modernização não contemplou todo o segmento da agricultura familiar, pois, a partir dos dados aqui apresentados, fica enfatizada tal condição, especialmente ao que respeita à cobertura do programa.

A trajetória do Pronaf no Estado apresenta uma tendência de continuidade desse quadro contraditório, que ao longo dos anos apresenta concentração nas culturas financiadas, pouca representatividade das linhas alternativas e principalmente perda da capilaridade em termos de cobertura do Programa. Ao seguir essa rota, o Programa que visava, em seu desenho inicial, a uma perspectiva de fortalecimento do segmento familiar, caminha em uma perspectiva de contribuir e/ou aumentar as desigualdades e a exclusão social no campo.

Essa continuidade dos rumos do programa pode ser alterada com uma ruptura do laissez-faire, laissez-passer atual por parte das entidades representativas dos atores que acessam e das instituições que operacionalizam o Programa. Nesse sentido é responsabilidade de todos repensar ações, práticas e políticas do Pronaf que possam proporcionar novos rumos e principalmente possibilitar o fortalecimento de um conjunto maior de agricultores familiares. Aliás, em tempo, o Pronaf na condição de política pública já nasceu com a diretriz democrática de participação e avaliação, que por algum motivo se perdeu em determinado momento.

Por fim, fomentar esse debate em torno do Pronaf é de fundamental importância para a compreensão da realidade social da agricultura familiar em termos de política pública. Esta e outras respostas podem ser obtidas em outros estudos que tenham o fim de aprofundar os questionamentos sobre os fenômenos que circundam este objeto de pesquisa.

Para tanto, porém, é necessário um novo pacto por parte dos atores e das instituições que operam o Programa, no sentido de uma nova trajetória, capaz de superar os aspectos levantados neste estudo e outros mais que se colocam no âmbito nacional, com o intuito de aprimorar a política pública e de fato alcançar o objetivo do programa em fortalecer o segmento da agricultura familiar brasileira.

\section{REFERÊNCIAS}

AQUINO, Joacir Rufino de; GAZOLLA, Márcio; SCHNEIDER, Sergio. O financiamento público da produção agroecológica e orgânica no Brasil: inovação institucional, obstáculos e desafios. In: SAMBUICHI, Regina Helena Rosa et al. A política nacional de agroecologia e produção orgânica no Brasil: uma trajetória de luta pelo desenvolvimento rural sustentável. Brasília: Ipea, 2017.

AQUINO, Joacir Rufino de; SCHNEIDER, Sergio. (Des)caminhos da política de crédito do Pronaf na luta contra pobreza e a desigualdade social no Brasil rural. In: CONFERÊNCIA NACIONAL DE POLÍTICAS PÚBLICAS CONTRA A POBREZA E A DESIGUALDADE, Natal, 2010. Anais [...]. Natal, RN, 2010.

AQUINO, Joacir Rufino de; SCHNEIDER, Sergio. O Pronaf e o desenvolvimento rural brasileiro: avanços, contradições e desafios para o futuro. In: GRISA, Catia; SCHNEIDER, Sergio (org.). Políticas Públicas de Desenvolvimento Rural no Brasil. Porto Alegre: UFRGS, 2015. p. 53-81.

BIANCHINI, Valter. Vinte Anos do Pronaf, 1995-2015: avanços e desafios. Brasília: SAF; MDA, 2015.

BRASIL. Banco Central do Brasil. Anuário Estatístico do Crédito Rural, 1996-2012. 2019a. Disponível em: http://www.bcb.gov.br. Acesso em: 19 mar. 2019.

BRASIL. Decreto n. 1.946, de 28 de junho de 1996. Cria o Programa Nacional de Fortalecimento da Agricultura Familiar - Pronaf, e, dá outras providências. Diário Oficial [da] República Federativa do Brasil, Brasília, DF, 1996. 
BRASIL. Lei n. 11.326 de 24 de julho de 2006. Estabelece as diretrizes para a formulação da Política Nacional de Fortalecimento da Agricultura Familiar e Empreendimentos Familiares Rurais. Diário Oficial [da] República Federativa do Brasil, Brasília, DF, 2006.

BRASIL. Matriz de Dados do Crédito Rural, 2013-2018. 2019b. Disponível em: http://www.bcb.gov.br. Acesso em: 19 mar. 2019.

BRUMER, Anita; SPANEVELLO, Rosani Marisa. O papel dos mediadores no acesso das mulheres ao Pronaf mulher. Revista Anthropológicas, v. 23, p. 97-117, 2012.

CAZELLA, Ademir Antonio et al. Políticas Públicas de Desenvolvimento Rural no Brasil: o dilema entre inclusão produtiva e assistência social. Política \& Sociedade, Florianópolis, v. 15, p. 49-79, 2016.

CRESWELL, John W. Projeto de pesquisa: métodos qualitativo, quantitativo e misto. 3. ed. Porto Alegre: Artmed, 2010.

DELGADO, Guilherme Costa. Capital financeiro e agricultura no Brasil: 1965-1985. São Paulo: Ícone, 1985. DENZIN, Norman K.; LINCOLN, Yvonna S. O planejamento da pesquisa qualitativa: teorias e abordagens. 2. ed. 1. reimp. Porto Alegre: Artmed, 2010.

EPAGRI; CEPA. Síntese Anual da Agricultura de Santa Catarina. Vários Anos. Florianópolis: Epagri/Cepa, anual, 2019. Disponível em: www.cepa.epagri.sc.gov.br. Acesso em: 12 maio 2019.

FAO; INCRA. Diretrizes de política agrária e desenvolvimento sustentável. Resumo do Relatório Final do Projeto UTF/BRA/036, segunda versão. Brasília, 1994.

FAVARETO, Arilson et al. Entre chapadas e baixões do Matopiba - dinâmicas territoriais e impactos socioeconômicos na fronteira de expansão agropecuária no Cerrado. 1. ed. São Paulo: Prefixo Editorial; Ilustre Editora, 2019. 272 p. V. 1.

FOSSÁ, Juliano Luiz et al. Percepções de trabalhadores da cooperativa de crédito rural cresol Chapecó: um estudo de caso sobre o Pronaf. Revista de Desenvolvimento Rural Interdisciplinar, Porto Alegre, v. 1, n. 1, maio/nov. 2018.

FOSSÁ, Juliano Luiz. O programa nacional de fortalecimento da agricultura familiar (Pronaf) para os agricultores familiares: dos alcances às percepções. 2015. Dissertação (Mestrado em Políticas Sociais e Dinâmicas Regionais) - Universidade Comunitária da Região de Chapecó, 2015.

GAZOLLA, Marcio; SCHNEIDER, Sergio. Qual "Fortalecimento" da agricultura familiar? Uma análise do Pronaf crédito de custeio e investimento no Rio Grande do Sul. RESR, Piracicaba, SP, v. 51, n. 1, p. 45-68, jan./mar. 2013.

GOULARTI FILHO, Alcides. Formação econômica de Santa Catarina. 3. ed. rev. Florianópolis: Ed. da UFSC, 2016.

GRISA, Catia; SCHNEIDER, Sergio. Três gerações de políticas públicas para agricultura familiar. In: GRISA, Catia; SCHNEIDER, Sergio (org.). Políticas Públicas de Desenvolvimento Rural no Brasil. Porto Alegre: UFRGS, 2015. p. 19-50.

IBGE. Instituto Brasileiro de Geografia e Estatística. Censo Agropecuário de 2006. Rio de Janeiro: IBGE, 2006.

IBGE. Instituto Brasileiro de Geografia e Estatística. Censo Agropecuário 2017. Rio de Janeiro: IBGE, 2019.

IBGE. Instituto Brasileiro de Geografia e Estatística. INPC - Índice Nacional de Preços ao Consumidor. 2018. Disponível em: https://www.ibge.gov.br/estatisticas-novoportal/economicas/precos-e-custos/9258-indice-nacional-de-precos-ao-consumidor.html?=\&t=series-historicas. Acesso em: 31 jan. 2019.

KOCHE, José Carlos. Fundamentos de metodologia científica: teoria da ciência e iniciação à pesquisa. 34 . ed. Petrópolis: Vozes, 2015.

MARCONI, Marina de Andrade; LAKATOS, Eva Maria. Metodologia científica. 7. ed. atual. São Paulo: Atlas, 2018.

MATTE, Alessandra; WAQUIL, Paulo Dabdab. Situações de vulnerabilidade na pecuária de corte no Rio Grande do Sul: entre políticas públicas e questões rurais atuais. Revista Grifos, Chapecó, SC, v. 27, n. 45, p. 225-245, jul./dez. 2018.

MATTEI, Lauro. Novo retrato da agricultura familiar em Santa Catarina. In: ENCONTRO DE ECONOMIA CATARINENSE, 4., 2010, Criciúma, Anais [...]. Criciúma: Apec, 2010.

MATTEI, Lauro. Políticas Públicas de Apoio à Agricultura Familiar: o caso recente do Pronaf no Brasil. Raízes, UFPB, v. 35, p. 1-15, 2015.

RAMBO, Fabiano Lazarotto. O Programa Pronaf Mais Alimentos: um estudo de caso da microrregião de Pinhalzinho (SC). 2014. 130 p. Dissertação (Mestrado em políticas sociais e dinâmicas regionais) - Universidade Comunitária da Região de Chapecó, 2014.

RENK, Arlene. A luta da erva: um ofício étnico da nação brasileira no oeste catarinense. 2. ed. rev. Chapecó: Argos, 2006. 
SANTO, Evelise Espirito. A agricultura no Estado de Santa Catarina. Chapecó, SC: Editora Grifos, 1999. SPANEVELLO, Rosani Marisa; MATTE, Alessandra; BOSCARDIN, Mariele. Crédito rural na perspectiva das mulheres trabalhadoras rurais da agricultura familiar: uma análise do Programa Nacional de Fortalecimento da Agricultura Familiar (Pronaf). Polis - Revista Latinoamericana, v. 15. p. 1-19 2016.

TOLEDO, Elizário Noé Boeira. O Pronaf em Salvador das Missões: contradições de uma política de crédito. 2009. 186 f. Dissertação (PGDR) - Universidade Federal do Rio Grande do Sul, Porto Alegre, 2009.

VENNET, Bert Vander; SCHNEIDER, Sergio; DESSEIN, Joost. Different farming styles behind the homogenous soy production in southern Brazil. The Journal of Peasant Studies, v. 43, n. 2, p. 396-418, mar. 2016.

WANDERLEY, Maria Nazaré B. Franja periférica, pobres do campo, camponeses: dilemas da inclusão social dos pequenos agricultores familiares. In: DELGADO, Guilherme Costa; BERGAMASCO, Sonia Maria Pessoa Pereira (org.). Agricultura familiar brasileira: desafios e perspectivas de futuro. 1. ed. Brasília: Ministério do Desenvolvimento Agrário, 2017. p. 66-83. V. 1.

WERLANG, Alceu Antonio. Disputas e ocupação do espaço no Oeste Catarinense: a atuação da Companhia Territorial Sul Brasil. Chapecó: Argos, 2006.

WINCKLER, Silvana Terezinha; RENK, Arlene Anelia. A luta do Movimento de Mulheres Camponesas (MMC) em defesa da biodiversidade e da autonomia dos agricultores. In: OLSSON, Giovanni; TEIXEIRA, Marcelo Markus; PEREIRA, Reginaldo; WINCKLER, Silvana. (org.). Educação jurídica, relações internacionais e cidadania ecológica. 1. ed. Chapeco: Argos Editora Universitária, 2013. p. 213-231. V. 1. 